\title{
Concept of intelligent system for controlling regenerative braking and using recovery energy
}

\author{
Alexander Vilgelm ${ }^{1, *}$, Mikhail Nikiforov ${ }^{1}$, and Vasily Cheremisin ${ }^{1}$ \\ ${ }^{1}$ Omsk State Transport University, 644046, Marx av., 35, Omsk, Russia
}

\begin{abstract}
The issue of increasing the level of electrical energy recovered by the electric rolling stock and the efficiency of its use at the electrified sections of railways of JSC "Russian Railways" is still topical at present. This issue is considered today in the context of increasing the efficiency of the use of traction rolling stock. Increasing the energy efficiency of the transportation process by increasing the efficiency of recovery can be achieved both by the implementation of organizational decisions and through the introduction of additional equipment in the traction power supply system, for example, installation of reversible converters at traction substations or power storage devices on electric rolling stock and in the system of traction power supply, as well as other technical means, changing the parameters of the operation of sections with mandatory provision of the operability of the regenerative braking systems in the electric rolling stock. To assist in the reasoned adoption of similar and other managerial decisions, it is advisable to create an intelligent system for controlling the processes of applying regenerative braking and using recovery energy. This paper briefly reviews the main results of scientific research on the efficiency of recovery, suggests a mechanism for adapting the methods developed earlier to the system for controlling energy efficiency of recovery processes at the sections of railways.
\end{abstract}

\section{Introduction}

Recently, among the employees of JSC "RZD" connected with the issues of traction of trains, there was an opinion that "the use of recovery is not only useless, but even harmful, because the recovered energy is not used efficiently and only heats the contact network and, moreover, when switching on the recovery, the traction substations are allegedly out of order" [1]. Of course, this is not true. However, in order to disprove this point of view, a number of experimental studies were carried out, which showed the energy efficiency of regenerative breaking. In particular, the experiment at the double-track section of direct current [2] showed a significant reduction in the specific energy consumption for traction of trains (according to meters at the traction substations) in case of using regenerative braking at the section. Flow distribution of recovery energy and the expediency of using reversible converters at the single-track section of the direct current are shown in the source [3], and the flow distribution of recovery energy at the section of the alternating current is shown in the source [4], the

*Corresponding author: vilgelm87@gmail.com 
expediency and efficiency of monitoring the voltage levels on the tires of traction substations to improve the efficiency of regenerative braking - in [5].

The foreign experience of applying regenerative braking is usually positive [6 - 8]. For example, on the UK railways, the share of return of recovery energy in the contact network is approximately $7.2 \%$ of the energy consumption for traction by meters of traction substations. At the same time, $1.7 \%$ of recovery energy is returned to the external power supply system. In Spain, the share of return of recovery energy in the contact network is $9.6 \%$ of energy consumption by traction substations. At the same time, the total percentage of return of recovery energy in the external power supply system for all electric power supply systems in Spain is approximately $2.6 \%$ of the consumed energy. The share of return of recovery energy in the contact network on the railways of Sweden is $8.3 \%$ of the energy consumption by traction substations. In all these cases, part of the braking energy of trains is also realized due to dynamic braking.

On the railway network of JSC "RZD", a similar analysis of the distribution of recovery energy with the allocation of its part that is used effectively will certainly become possible with the organization of an automated system for monitoring the energy efficiency of the transportation process [9] which, in addition, will also solve most of the problems related to the control of recovery processes and increasing its efficiency. However, to date, the issues of automated analysis of the efficiency of regenerative braking are usually reduced to statistical processing based on the data from the driver's route sheets on the results of trips made by locomotive crews [10]. A general classification of methods form assessing the efficiency of regenerative breaking was carried out in [11]. Until the present time, there were no mechanisms for analyzing the recovery energy distribution flow in the traction power supply system (TPSS) without the organization of experimental operating domains (taking into account the absence of stationary systems of synchronous measurements of electric quantities in traction substations and rolling stock on the railway network).

It is also necessary to understand that two main directions can be identified in the problem of control of recovery processes [12]:

- control of the processes of application of regenerative braking by electric rolling stock (ERS) during the movement of trains on sections;

- adoption of managerial, organizational and technical solutions for maximizing the effective use of generated by ERS recovery energy in TPSS, by trains running in traction mode, and for the own needs of recovering ERS.

The purpose of this work is to create conceptual approaches to the formation of an intelligent system for controlling regenerative braking processes, which is a kind of information and analytical decision support system [13,14]. To do this, it is necessary to analyze the possibilities of existing developments in the field of analysis of energy efficiency of using recovery energy $[2,15-20]$ and propose a general algorithm for the operation of such an intelligent system.

\section{Object and methods of research}

It can be concluded from the above that one of the main purposes of recovery is the ability to reduce electric power consumption from traction substations for traction of trains. In JSC "RZD", this is achieved both due to the intensification of the application of regenerative braking on ERS and also due to a set of measures to increase the efficiency of the use of recovery energy generated by ERS in TPSS. So, according to the Energy Strategy of the Russian Railways Holding, the main reasons for the annual increase in the amount of recovery are:

- electrification of individual sections with a complex track profile;

- restoration and modernization of regenerative braking systems; 
- renewal of the fleet of ERS (purchase of new electric locomotives 2ES6, 2ES10, 2ES5K, electric trains ES2G, etc., more effectively implementing regenerative braking);

- introduction of reversible converters of a new generation in traction substations of direct current;

- strengthening control over the use of regenerative braking;

- revision of normative documents and parameter tables in the part of the application of recuperative braking.

Undoubtedly, all these measures serve to increase both the level of recovery of ERS and the level of efficiency of its use. At the same time, the reporting level of recovery in JSC "RZD", which today exceeds 2 billion $\mathrm{kW} \mathrm{h}$, is the return of recovery energy by the meters of ERS, i.e. meters of the technical account of energy. Even though to calculate the economic efficiency of the recovery, it would be correct to take into account the effective component of the recovery, namely the amount of energy consumption reduction by the meters of traction substations due to the use of recovery.

In order to solve this problem, especially for the purpose of assessing the degree of efficiency of the use of the generated by ERS recovery energy, four integrated mathematical models for the operation of electrified sections were developed in the Omsk State Transport University (OmGUPS)[15]:

- model of operation of double-track sections of direct current;

- model of operation of double-track sections of alternating current;

- model of operation of single-track sections of direct current;

- model of operation of single-track sections of alternating current.

The models are based on simulation modeling of traction calculations, train traffic schedules, and electrical calculations of TPSS and are a convenient mechanism for analyzing the flow of recovery energy distribution in TPSS. With the help of the developed mathematical models, the following was performed:

- assessment of the influence and mutual influence of factors that determine the efficiency of recovery;

- development of a methodology and an algorithm for determining the efficiency of using recovery energy for own needs of recovering ERS;

- development of a methodology and an algorithm for assessing the difference in energy losses in TPSS in cases with the use of recovery at the section and without using it[19];

- development of an algorithm for determining the efficiency of using recovery energy at the sections of railways, taking into account the energy consumption of recovery for the own needs of the recovering ERS and the value of the change in energy losses in TPSS in cases with the use of regenerative braking at the section and without using it.

A detailed description of the mathematical models, the studies performed on their basis and their results are given in the source [15].

Numerical values of operational factors and characteristics of TPSS are used in algorithms as initial data for calculations. An algorithm for determining the efficiency of using recovery energy is based on the sequential calculation of five factors that depend on the operational factors and characteristics of TPSS and allow determining the balance of the recovery energy generated at the section with its distribution by the components of efficient use and energy losses in TPSS (Figure 1). 


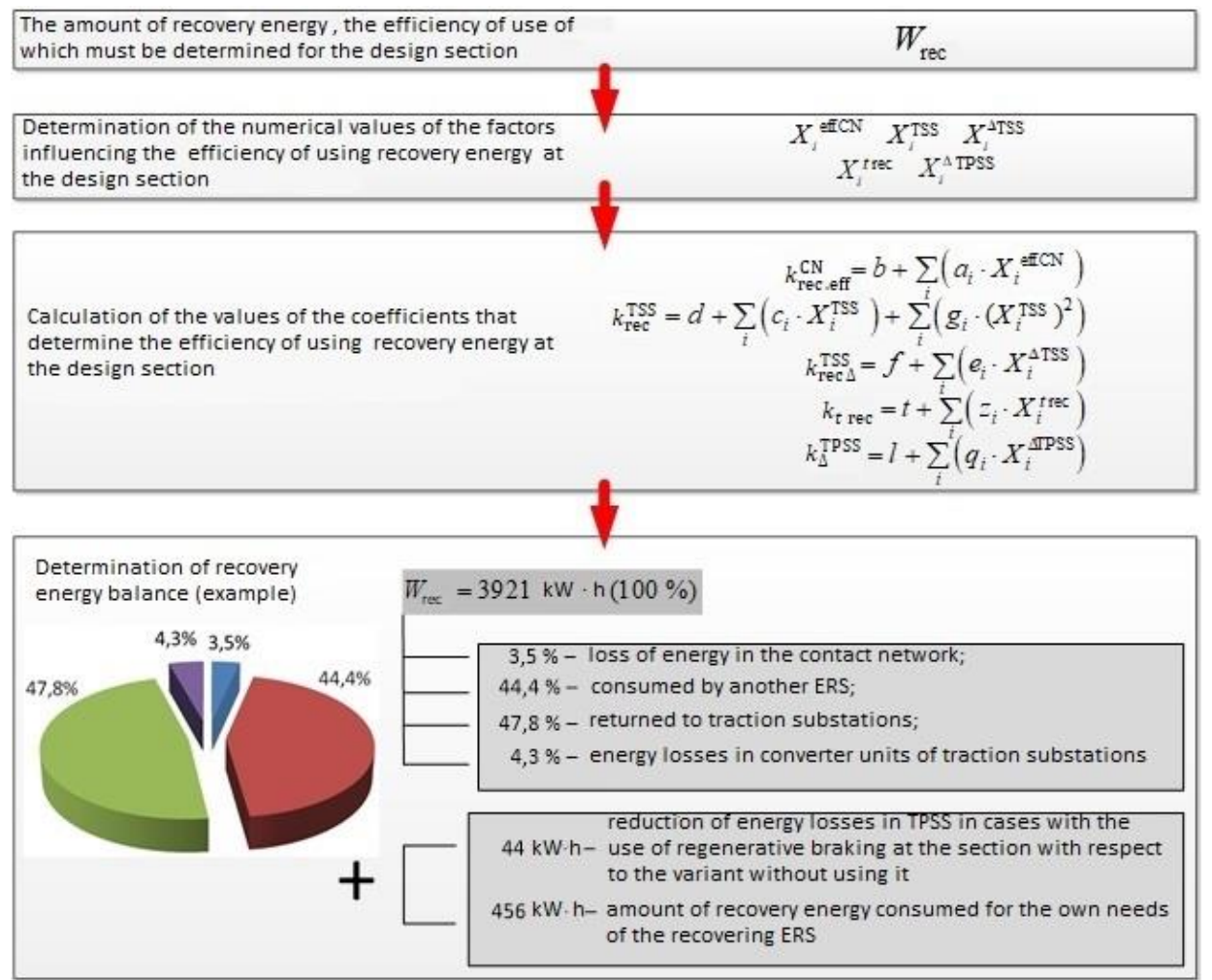

Fig. 1. Algorithm of the theoretical model for the assessment of efficiency of using recovery energy with an example of determination of recovery energy balance for the railway section.

According to the algorithm presented in Figure 1, any reporting value of the energy recovered by ERS in the contact network Wrec (whether it is the value per trip or the total value, for example, for the month, quarter or year for the haul distance of the locomotive crews) can be accepted for calculation, and, proceeding from it and also from the set of values of various factors $\left(\mathrm{X}_{\mathrm{i}}^{\text {eff.CN }}, \mathrm{X}_{\mathrm{i}}^{\mathrm{TSS}}, \mathrm{X}_{\mathrm{i}}^{\Delta \mathrm{TSS}}, \mathrm{X}_{\mathrm{i}}^{\mathrm{t} \text { rec }}, \mathrm{X}_{\mathrm{i}}^{\Delta \text { TPSS }}\right.$ ) on the section under consideration in the period under consideration, determine its balance with the allocation of:

- shares used efficiently and, consequently, reducing energy consumption from traction substations;

- shares that make up the loss of recovery energy;

- the amount of recovery energy consumed for the own needs of the recovering ERS and not accounted for by its meters;

- the value of the energy loss difference in TPSS in cases with the use of regenerative braking at the section and without using it.

This is done using the following empirical coefficients:

- coefficient of efficiency of using recovery energy, minus its losses in the contact network $\mathrm{k}_{\text {rec.eff }}^{\mathrm{CN}}$;

- coefficient of return of recovery energy to traction substations $\mathrm{k}_{\mathrm{rec}}^{\mathrm{TSS}}$;

- coefficient of loss of recovery energy in converter units of traction substations $\mathrm{k}_{\mathrm{rec} \Delta}^{\mathrm{TSS}}$;

- coefficient of residence time of ERS in the recovery mode $\mathrm{k}_{\mathrm{trec}}$, to determine the amount of recovery energy consumed for the own needs of the recovering ERS;

- coefficient of the difference in energy losses in TPSS for cases with and without the use of recovery $\mathrm{k}_{\Delta}^{\mathrm{TPSS}}$. 
To calculate the empirical coefficients, the auxiliary coefficients ai, b, t, zi, d, ci, gi, f, ei, 1, qi are used that are determined separately for the four theoretical models created on the basis of results of the correlation analysis of the influence of factors $X_{i}^{\text {eff.CN }}, X_{i}^{\text {TSS }}, X_{i}^{\Delta T S S}, X_{i}^{t ~ r e c}, X_{i}^{\Delta T P S S}$ on the values of the empirical coefficients $k_{\text {rec.eff }}^{\text {CN }}, k_{\text {rec }}^{\text {TSS }}$, $\mathrm{k}_{\mathrm{rec} \Delta}^{\mathrm{TSS}}, \mathrm{k}_{\mathrm{t} \text { rec }}, \mathrm{k}_{\Delta}^{\text {TPSS }}$ based on the simulation modeling of the work of electrified sections.

\section{Results}

The calculation and analytical method described above is expedient and effective in the absence of the possibility of carrying out synchronous measurements of current consumption processes on railway sections. Such measurements are feasible only if there is time reference measuring equipment at the traction substations and ERS and GPS/GLONASS systems on ERS, installation of which is very expensive. At the same time, the studies carried out on the basis of this method gave certain results (some of which will be considered below), which justify the possibility and expediency of automating the processes of controlling the efficiency of regenerative braking on railway sections.

Table 1. Main performance indicators at the section and the characteristics of the current double-track section of direct current.

\begin{tabular}{|c|c|c|c|}
\hline $\mathrm{N}$ & Indicator name & Value & $\begin{array}{l}\text { Unit of } \\
\text { measurement }\end{array}$ \\
\hline 1 & $\begin{array}{l}\text { Volume of recovery for all series of ERS of the depot under consideration } \\
\text { at the design period at the design section }\end{array}$ & 458700 & $\mathrm{~kW} \cdot \mathrm{h}$ \\
\hline 2 & Total amount of transportation for all series of ERS & 65100 & $\begin{array}{l}10^{4} \mathrm{tkm} \\
\text { gross }\end{array}$ \\
\hline 3 & Ruling gradient in odd direction & 12,0 & $\%$ \\
\hline 4 & Ruling gradient in even direction & 10,0 & $\%$ \\
\hline 5 & Average mass of freight trains in odd direction & 5000 & $\mathrm{t}$ \\
\hline 6 & Average mass of freight trains in even direction & 2000 & $\mathrm{t}$ \\
\hline 7 & Average technical speed of freight traffic & 45,0 & $\mathrm{~km} / \mathrm{h}$ \\
\hline 8 & Average service speed of freight traffic & 40,0 & $\mathrm{~km} / \mathrm{h}$ \\
\hline 9 & Average number of pairs of trains per day for all types of traffic & 50 & pairs \\
\hline 10 & Average number of pairs of trains per day for freight traffic & 30 & pairs \\
\hline 11 & Number of traction substations at the section & 9 & pes. \\
\hline 12 & Number of traction substations with reversible converters at the section & 2 & pes. \\
\hline 13 & $\begin{array}{l}\text { Weighted average relative resistance of the contact suspension of the } \\
\text { section }\end{array}$ & 1,56 & r.u. \\
\hline 14 & $\begin{array}{l}\text { Weighted average coefficient of reserve of working capacity of a contact } \\
\text { wire line of a section }\end{array}$ & 0,85 & r.u. \\
\hline 15 & $\begin{array}{l}\text { Weighted average relative resistance of the contact network of the design } \\
\text { section, depending on the power supply circuits of the zones between } \\
\text { substation }\end{array}$ & 1,137 & r.u. \\
\hline 16 & $\begin{array}{l}\text { Average power of idling losses of converter transformers of traction } \\
\text { substations }\end{array}$ & 16 & $\mathrm{~kW}$ \\
\hline 17 & $\begin{array}{l}\text { Average power of short circuit losses of converter transformers of traction } \\
\text { substations }\end{array}$ & 55 & $\mathrm{~kW}$ \\
\hline 18 & $\begin{array}{l}\text { Amount of recovered energy by the meters of SPS (secondary power } \\
\text { supply) inputs of traction substations }\end{array}$ & 95400 & $\mathrm{~kW} \cdot \mathrm{h}$ \\
\hline
\end{tabular}


As an example, let us consider the results of calculations of the efficiency of using the energy recovered by ERS of an operating depot on an active double-track section of direct current with a complex track profile. The level of specific recovery by ERS of this depot in the design period at the design section was $7.05 \mathrm{~kW} \mathrm{~h} / 104 \mathrm{tkm}$ gross, the main performance indicators at the section and the characteristics of the section are given in Table 1.

In Table 1, the weighted average relative resistance of the contact suspension of the section is defined as the ratio of the sum of the products of the relative resistance of the contact suspension for each type of contact suspension of the design section (in rel.un.) and the length of the track section of the specified type to the total track length of the section. The weighted average reserve capacity coefficient of the contact wire line of the section is defined as the ratio of the sum of the products of the working capacity coefficients of the contact wire line of each part of the track of the design section (in rel.un., for example: if the wear of wire line is $25 \%$ - the reserve coefficient is assumed to be 0.75 ) and the track length with the corresponding coefficient of reserve to the total track length of the entire section. The average weighted relative resistance of the contact network of the design section, depending on the power supply circuits of the zones between substations, is defined as the ratio of the sum of the products of the relative resistance of the contact suspension for each zone between substations of the design section (in rel.un.) and the length of the corresponding zone between substations to the total track length of the section [15].

Thus, at the section under consideration, a contact suspension of the PBSM-95+2MF$100+\mathrm{A} 185$ type is used, and the weighted average relative resistance of the contact suspension in this case is 1.56 . The nodal powering mode of the zones between substations of the section corresponds to the weighted average relative resistance of the contact network equal to 1.137. In case of these characteristics, the balance of recovery energy (458 700 $\mathrm{kW} \mathrm{h}$ ) was as follows (Fig. 2).

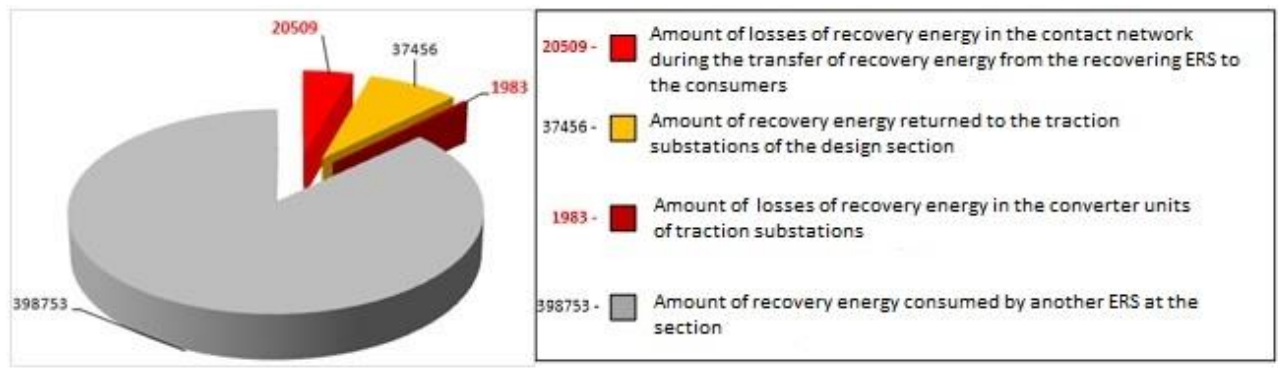

Fig. 2. The balance of energy recovery in the design section $(\mathrm{kW} \mathrm{h})$ with the current parameters and characteristics.

Figure 2 shows that $436209 \mathrm{~kW} \mathrm{~h}(398753+37456)$ of recovery energy was used efficiently: it was consumed by other trains and returned to traction substations, minus energy losses in the contact network and converter units of traction substations. The loss of recovery energy in the contact network at the same time amounted to $20509 \mathrm{~kW} \mathrm{~h}(4.47 \%$ of the total recovered energy), the loss of recovery energy in the converter units of traction substations $-1983 \mathrm{~kW} \mathrm{~h}(0.43 \%$ of the total recovered energy).

The type of the contact suspension and the power circuit of the traction network have a significant influence on the level of recovery energy losses in the traction network and the amount of recovery energy returned to the traction substations of the section [15, subsection $2.2,20]$. So, if we strengthen the contact network with an additional amplifying wire A-185, i.e. use a contact suspension of the PBSM-95+2MF-100+2A185 type with a weighted average relative resistance of 1.19 , the recovery energy losses in the contact network will be reduced by almost half to the value of $11537 \mathrm{~kW} \mathrm{~h}(2.54 \%$ of the total recovered energy), 
and the recovery energy losses in the regenerative units of traction substations will increase insignificantly to $2396 \mathrm{kWh}(0.52 \%$ of the total recovered energy). At the same time, the amount of recovery energy transferred by ERS to the contact network and used effectively will increase to $444667 \mathrm{~kW} \mathrm{~h}$.

If we take into account the contact suspension of the M-120+2MF-100+2A185 type with a weighted average relative resistance of 1.00 , the energy losses of the recovery in the contact network will be reduced by another $1 \%$ to a value of $7.081 \mathrm{~kW} \mathrm{~h}(1.54 \%$ of the total amount of recovered energy), the loss of recovery energy in the converter units of traction substations will increase to a value of $2731 \mathrm{~kW} \mathrm{~h}(0.60 \%$ of the total recovered energy). In this case, the amount of recovery energy transferred by ERS to the contact network and used effectively will increase to a value of $448888 \mathrm{~kW} \mathrm{~h}$.

However, if one takes into account one of the two additional components of the effect, namely the value of the change in the energy losses in TPSS, released by the traction substations in the regenerative braking mode with respect to the mode without recovery, the situation with the efficiency of the recovery will change when the type of the contact suspension changes.

Figure 3 shows a diagram of changes in the losses of recovery energy in the contact network and in the converter units of traction substations and changes in energy losses in TPSS with and without the use of regenerative braking, depending on the type of contact suspension.

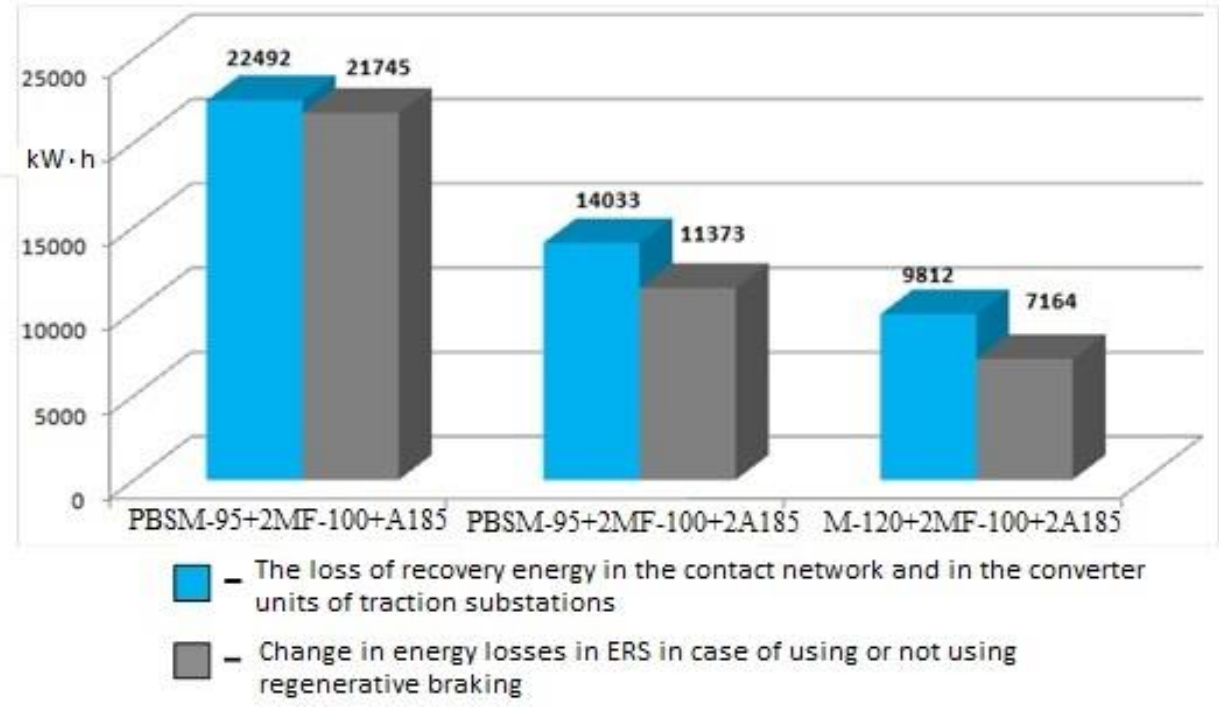

Fig. 3. Diagram of change in the energy losses on a section, depending on type of a contact suspension.

Figure 3 shows that the value of the total energy losses in the contact network and in the converter units decreases with a decrease in the specific resistivity of the traction network, as described above. At the same time, the change in energy losses in TPSS in the mode of recovery using a contact suspension of PBSM-95+2MF-100+A185 type amounted to 21745 $\mathrm{kW} \mathrm{h}$ in the direction of reducing energy losses. As can be seen from figure 3 , this value is reduced with the change in the contact suspension, and is reduced more significantly than the losses of recovery energy do. The value of the total energy effect at the design section for the basic version of the calculation was $459233 \mathrm{~kW}$ h of energy saving due to the use of recovery. If the contact suspension is replaced with the suspension of PBSM-95+2MF$100+$ A185 type, the total energy effect will be reduced by $0.42 \%$ to $457319 \mathrm{~kW} \mathrm{~h}$, and for 
the suspension of M-120+2MF-100+2A185 type, the reduction in the total the energy effect will be comparable. It will be $457332 \mathrm{~kW}$ h.

Thus, the strengthening of the contact suspension in order to reduce the overall resistance of the traction network for a given section, while other factors remain unchanged, if the value of the effect is reduced to energy saving by the meters of traction substations, will not lead to an increase in the efficiency of using the recovery energy.

A similar analysis can be performed for the cases of changing the power supply circuits of the zones between substations, the size of the train traffic, the technical and service speed, the average mass of the trains and other parameters together or separately.

For example, the level of recovery energy losses in the traction network and the efficiency of using the recovery energy at the AC and DC sections are affected by the size of the train traffic, especially freight trains, and for DC sections, the average mass of freight trains in a more complex direction (even or odd) of train traffic and technical speed of freight traffic $[15$, subsection $2.3,19]$.

Or, for example, with an increase in the mass of trains, the average speed of train traffic at the section decreases, which has a significant effect on the residence time of ERS in the recovery mode [15, subsection 2.4]. At the same time, with increasing average speed, the percentage of time in the recovery mode increases. Thus, the increase in the mass of the trains at the section with a decrease in technical and service speed adversely affects the period of time in the regenerative braking mode in the total time of ERS movement, and the increase in the technical and service speed with an unchanged or decreasing average mass of freight trains leads to an increase in this proportion.

These examples - only selective from the set - show the complexity and multivariance of the influence of various factors on the efficiency of using recovery energy. The calculation and analytical method proposed in the paper makes it possible to perform a detailed analysis of the effect of similar and other changes in the parameters of the section operation on energy efficiency. On the basis of this calculation and analytical method, it becomes possible to perform an operational assessment and forecasting the efficiency of the TPSS operation, the organization of train traffic, the operation of the locomotive service, depending on the actual or planned changes in parameters and characteristics of the sections. The purpose of this assessment is to help in making managerial and organizational decisions on the justified intensification of the application of regenerative braking and the introduction of measures aimed at increasing the efficiency of using the already generated recovery energy.

\section{Discussion}

In order to achieve the above goal and increase the energy efficiency of the transportation process, it is generally proposed to automate the method described in the paper - to develop and implement the Automated System for Assessing the Efficiency of Using Recovery Energy at the Railway Sections (ASA EURE), which should become an integral part of the Intelligent Control System for Regenerative braking and the use of recovery energy (ICS R).

ASA EURE should interact with already existing systems, such as the SAS-portal (in which TCO-125 reporting is generated), GID "Ural", ACS-E, ACS-P and others, which contain the necessary initial information for calculating the empirical coefficients, which determine the character of the recovery energy distribution at the section.

The function diagram of the ICS R including the ASA EURE is shown in Figure 4. 


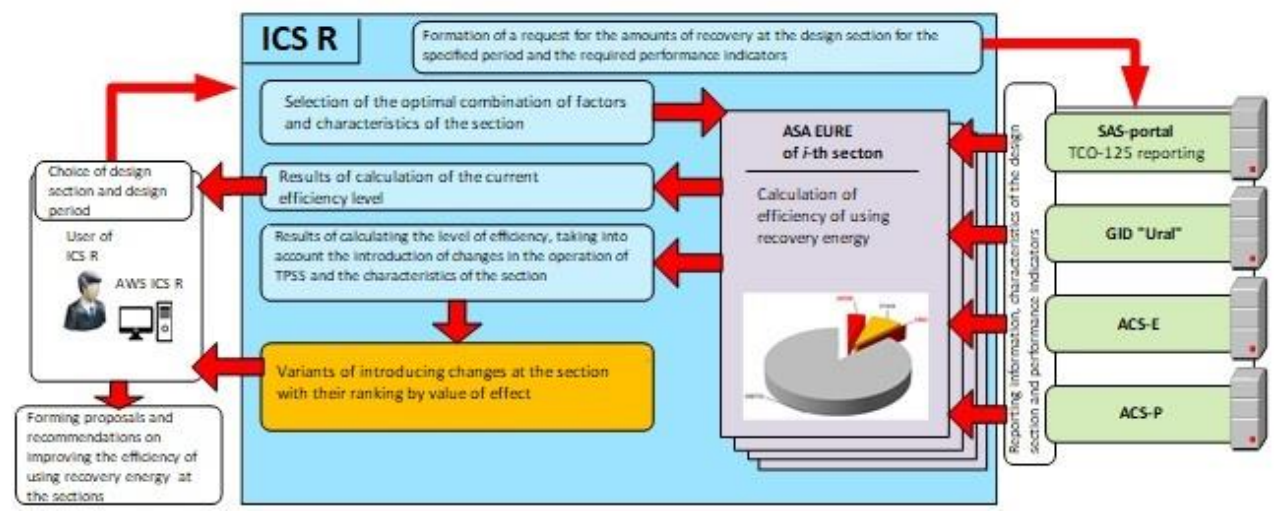

Fig. 4. Function diagram of the ICS R of the railway.

ICS R operates according to the following algorithm:

1) using an automated workstation (AWS ICS R), the user of ICS R determines the section of the railway (for example, any haul distance of the locomotive crews) and the period (calendar month, quarter or year) for which it is necessary to perform the analysis of efficiency of using recovery energy at the selected section;

2) ASA EURE receives information on the amount of recovery at the selected section for the specified period and other operational indicators from the TCO-125 reporting contained in the SAS-portal, and also information on the necessary for calculation operational data and characteristics of the section from the systems GID "Ural", ACS-E, ACS-P, etc .;

3) ASA EURE calculates the efficiency of using the recovery energy with the allocation of the amount of recovery energy consumed for the own needs of the recovering ERS, the traction of the other trains, returned to the traction substations with breakdown by connections, as well as the losses of recovery energy in the elements of TPSS;

4) ICS R selects the optimal combination of factors and characteristics of the section to reduce the level of recovery energy losses and increase the efficiency of its use with mandatory retention of energy recovered by ERS at the section;

5) ICS R forms several variants of changes in the modes of operation of TPSS, power supply circuits of sections, the organization of train traffic and options for introducing additional equipment in TPSS and ranks them according to the value of the effect;

6 ) on the basis of the analysis of the efficiency of using the recovery energy at the section for different reporting periods and the options proposed by the ICS R for the introduction of changes, the user of the ICS R determines the list of recommendations concerning organizational and managerial decisions, as well as the introduction of additional equipment in TPSS - SPS or energy storage.

\section{Conclusions}

The above ICS R system should not be limited by the functions described above. The paper presents only the mechanism for adaptation of developed in OmGUPS (and approved in JSC "RZD") methodology for assessing the efficiency of using recovery energy to the processes of managing the energy efficiency of the transportation process. An integral part of the ICS $\mathrm{R}$ can also be, for example, a system for comparing the results of actual trips at sections with energy diagrams of these sections [21] or even a system of real-time information of the driver about the situation at the section and the possibility of using regenerative braking, as well as other systems. Also, the ICS R should interact with other systems, for example, with the 
Intelligent Automated System for the Monitoring of Railway Areas with a Low Transport Process Energy Efficiency [22] currently being developed at OmGUPS or others.

In addition, taking into account the fact that the design models described in the paper are created for four scaled-up versions of sections (single-track/double-track, direct/alternating current), it makes sense to create mathematical models individually for each electrified section of railways (this will improve the accuracy of calculations for specific sections) and, accordingly, develop for them expressions for calculating empirical coefficients, determine the values of the auxiliary influence factors. It is these derived expressions and coefficients that should be further applied in the ASA EURE for calculations at specific sections.

It is also necessary to understand that as the change in one parameter or factor can lead to a change in the others, it is also necessary to develop the principles for the interconnection of operational factors and technical characteristics of railway sections and a correct algorithm for their changes, including recommendations for restrictions on their changes. This is the next task in further research on the development of the ICS R system to improve the energy efficiency of the use of electric rolling stock.

\section{References}

1. V.D. Tulupov, D.V. Minaev, Railway transport 5, 47 - 50 (2010)

2. V.T. Cheremisin, M.M. Nikiforov, Increasing the energy efficiency of regenerative braking at the operating domain of direct current: Scientific monograph (Omsk State Transport University,Omsk, 2016)

3. A.S. Vilgelm, A.N. Larin, Izvestiya Transsiba 1(5), 50 - 56 (2011)

4. Yu.V. Kondratiev, A.S. Vilgelm, A.N. Larin, Lokomotiv 5, 33 (2011)

5. V.A. Kvaschuk, A.S. Vilgelm, Innovative development of the Russian railway transport: Proceedings of All-Russian scientific-practical conference, Omsk, 119 - 127 (2012)

6. I. Gonzalez, E. Pilo, Energy Recovery Workshop, http://uic.org/forms/ IMG/pdf/regenerative_braking_traction_systems.pdf

7. URL: http://uic.org/forms/IMG/pdf/20150929_uic_workshop_tassin.pdf

8. URL: http://uic.org/ forms/IMG/pdf/recovery_system_jr_east.pdf

9. V.T. Cheremisin, S.Yu. Ushakov, Railway transport 3, 45-49 (2015)

10. E.A. Sidorova, A.I. Davydov, Lokomotiv 5(653), 30-32 (2011)

11. V.T. Cheremisin, M.M. Nikiforov, A.S. Vilgelm, Izvestiya Transsiba 1(25), 60 - 70 (2016)

12. A.A. Baklanov, V.L. Nezevak, A.P. Shatokhin, Vestnik RGUPS, Rostov-on-Don 1, 26 -33 (2016)

13. M.M. Nikiforov, Electrification, development of electric power infrastructure and electric rolling stock of speed and high-speed railway transport: proceedings of VIII intern. symp. "Eltrans 2015” (FSBEI HE PGUPS, St. Petersburg, 2017)

14. V.T. Cheremisin, M.M. Nikiforov, Abstracts of the IX International Symposium Eltrans2017 (FSBEI HE PGUPS, St. Petersburg, 2017)

15. V.T. Cheremisin, M.M. Nikiforov, A.S. Vilgelm, Efficiency of the use of recovery energy on railroads of direct and alternating current: Scientific monograph (Omsk State Transport University, Omsk, 2018)

16. V.T. Cheremisin, M.M. Nikiforov, A.S. Vilgelm, Transport Urala 3(50), 95 - 99 (2016)

17. V.T. Cheremisin, M.M. Nikiforov, A.S. Vilgelm, Vestnik RGUPSDon 1(65), 114-120 (2017) 
18. V.T. Cheremisin, M.M. Nikiforov, A.S. Vilgelm, Mir transporta 1(74), 34 - 45 (2018)

19. A.S. Vilgelm, M.M. Nikiforov, Transport Urala 2(53), 55 - 60 (2017)

20. M.M. Nikiforov, A.S. Vilgelm, V.I. Gutnikov, Izvestiya Transsiba 1(29), 74 - 83 (2017)

21. A.S. Vilgelm, A.L. Kashtanov, M.M. Nikiforov, Izvestiya Transsiba 2(10), 63 - 68 (2012)

22. V. Cheremisin, V. Nikiforov, A. Kashtanov, S. Ushakov, Advances in Intelligent Systems and Computing, 692, 83 - 91 (2017) 